\title{
Planarizing Material for Reverse-Tone Step and Flash Imprint Lithography
}

\author{
Tsuyoshi Ogawa ${ }^{1}$, Satoshi Takei ${ }^{2}$, B. Michael Jacobsson ${ }^{1}$, Ryan Deschner ${ }^{1}$, William Bell ${ }^{1}$, \\ Michael W. Lin', Yuji Hagiwara ${ }^{1}$, Makoto Hanabata ${ }^{2}$, C. Grant Willson ${ }^{1}$ \\ ${ }^{1}$ The University of Texas at Austin, Austin, Texas USA \\ ${ }^{2}$ Nissan Chemical Industries, Ltd, Funabashi, Chiba Japan
}

\begin{abstract}
Reverse-tone Step and Flash Imprint Lithography (S-FIL/R) requires materials that can be spin coated onto patterned substrates with significant topography and that are highly-planarizing. Ideally, these planarizing materials must contain silicon for etch selectivity, be UV or thermally curable, have low viscosity, and low volatility. One such novel material in particular, a branched and functionalized siloxane ( $\mathrm{Si}-12)$, is able to adequately satisfy the above requirements.

This paper describes a study of the properties of epoxy functionalized Si-12 (epoxy-Si-12) as a planarizing layer. An efficient synthetic route to epoxy-Si-12 was successfully developed, which is suitable and scalable for an industrial process. Epoxy-Si-12 has a high silicon content $(30.0 \%)$, low viscosity $\left(29 \mathrm{cP} @ 25^{\circ} \mathrm{C}\right)$, and low vapor pressure $(0.65$ Torr @ $25^{\circ} \mathrm{C}$ ). A planarizing study was carried out using epoxy-Si-12 on trench patterned test substrates. The material showed excellent planarizing properties and met the calculated critical degree of planarization (critical DOP), which is a requirement for a successful etch process. An S-FIL/R process using epoxy-Si-12 was demonstrated using, an Imprio ${ }^{\circledR}$ 100 (Molecular Imprints Inc., USA) imprint tool. The results indicate that epoxy-Si-12 works very well as a planarizing layer for S-FIL/R.
\end{abstract}

Keywords: Planarization, UV cure, siloxane, imprint, S-FIL/R, epoxy

\section{INTRODUCTION}

Step and Flash Imprint Lithography (S-FIL ${ }^{\circledR}$ ), is one of the candidates for the fabrication of nanoscale structures such as patterned media, MEMS devices and IC devices [1]. S-FIL has a strong advantage over EUV and other proposed optical lithography processes in terms of cost of ownership [2]. This is because there is no need for costly optics, and an expensive light source. In addition, multi-level structures can be fabricated simultaneously, which offers great cost saving in the back end of the line [3]. The S-FIL process is illustrated in Figure 1 below.

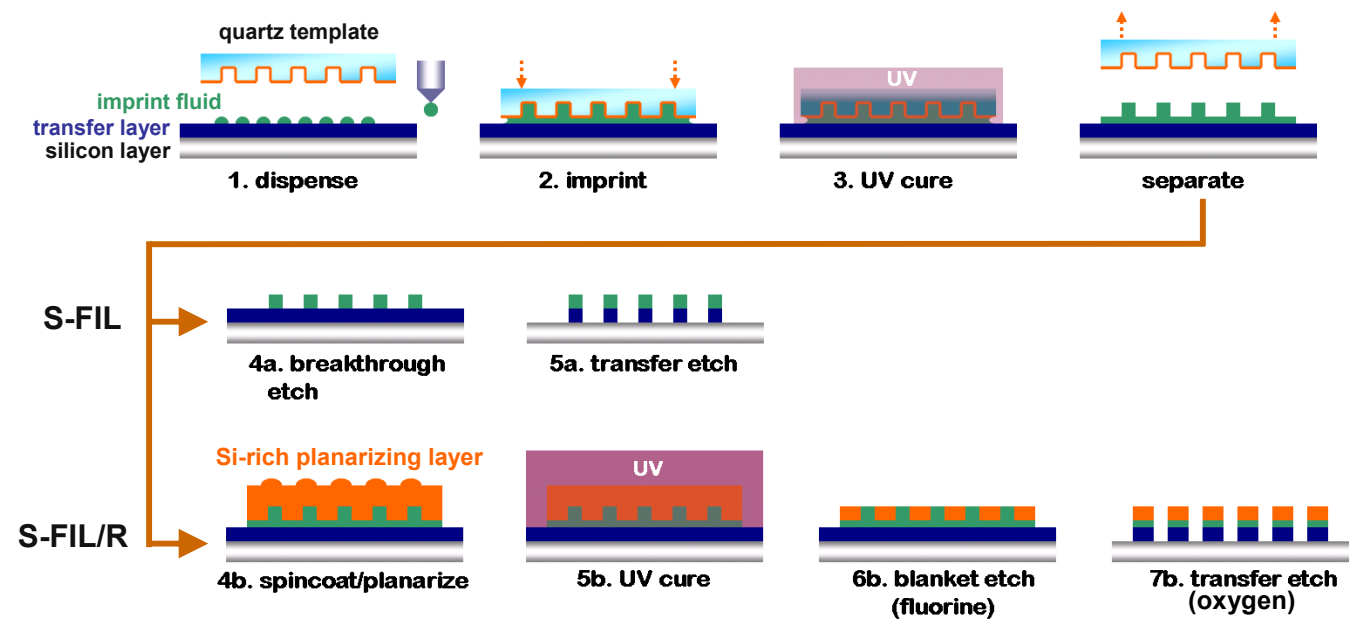

Figure 1. The Step and Flash Imprint Lithography process

Alternative Lithographic Technologies II, edited by Daniel J. C. Herr, Proc. of SPIE Vol. 7637

763708 - (C) 2010 SPIE · CCC code: $0277-786$ X/10/\$18 · doi: $10.1117 / 12.846430$ 
The process is divided can take two different paths. The first is a traditional imprint process (S-FIL) and the other is a reverse-tone S-FIL process called S-FIL/R. The S-FIL/R process is superior to traditional S-FIL because of a much wider process window (high tolerance to a variety of topographic surfaces, which solves the residual layer uniformity and thickness issues) and a possibility to yield high aspect ratios [4]. However, S-FIL/R requires an additional layer, a planarizing layer with high silicon content that is resistant to an $\mathrm{O}_{2}$ plasma etch. This paper describes the development of such a planarizing material.

\section{MATERIALS}

The material requirements for a planarizing material are outlined in Figure 2. First, it should be resistant to an $\mathrm{O}_{2}$ plasma etch process, and therefore a high silicon content of $12 \%$ is needed. Other properties such as low viscosity and low vapor pressure are required to achieve good planarization of topography. We have previously reported the advantages of spin coating without a solvent to achieve planarization [5]. In this case, the liquid material does not undergo a compositional change during the spin coating, thus it can be allowed to sit and planarize under surface tension forces to any desired extent after spin coating and then hardened or cured by exposure to light. Therefore, both low viscosity and low vapor pressure are important material properties. The material must incorporate structural elements that render it curable under UV exposure. There are many functional groups that crosslink under UV light. For example, epoxy, acryloyl and vinyl functionality have all been exploited for this purpose. Considering all of these requirements led to the conclusion that branched siloxanes were strong candidates for UV curable planarizing materials.

\section{1) Highly $\mathrm{O}_{2}$ etch resistance \\ $\checkmark$ Si containing material}

\section{2) Good planarizing property}

$\checkmark$ Liquid material with low viscosity \& low vapor pressure

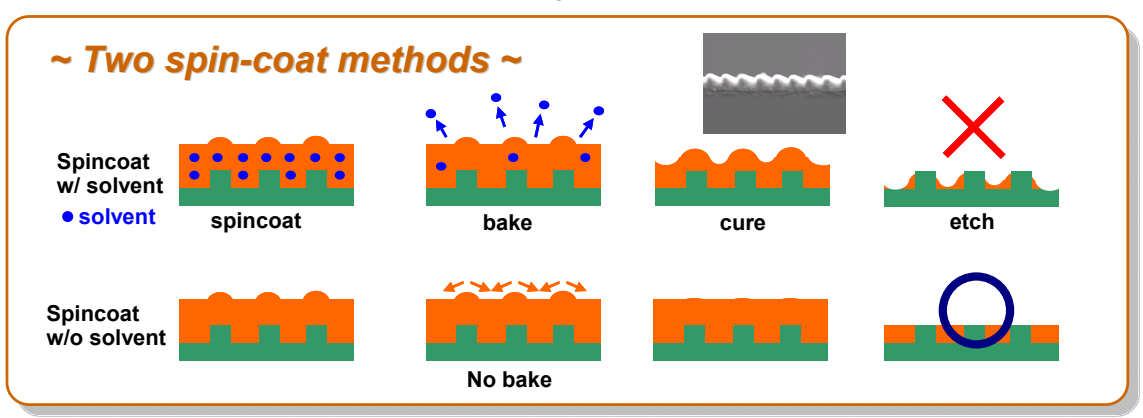

\section{3) Photo-curable \& low shrinkage material \\ $\checkmark$ Epoxy, acryl and vinyl ...}

Figure 2. Requirements for a planarizing material

The design of a UV curable branched siloxane was based on previous research carried out in our laboratories. We have reported one such material, Si-14 in an earlier publication [6]. Si-14 is a high molecular weight molecule (1276.48 Daltons) which serves to reduce the vapor pressure and it is branched, which leads to lower viscosity. The siloxane structure contributes to the high silicon content. Methacryl groups were selected as the UV curable component because of synthetic accessibility. Si-14 showed excellent planarizing properties, but the synthetic route to Si-14 required many steps and gave very poor overall yield $(<16.0 \%)$. The characterization of $\mathrm{Si}-14$ was also tedious because of all the steps that were involved. We now report $\mathrm{Si}-12$, an analog of $\mathrm{Si}-14$ and a convenient synthetic path that has been developed to provide that compound in high yield. 


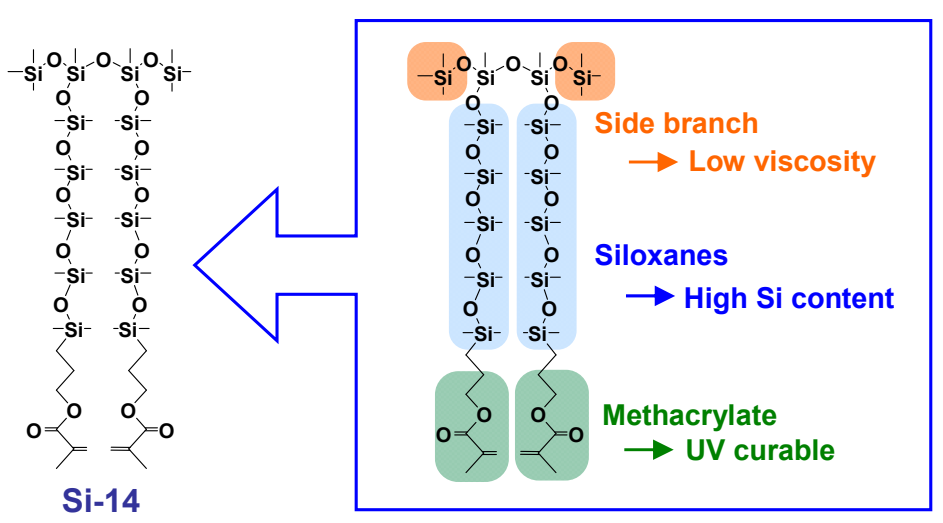

Figure 3. UV curable branched siloxane, Si-14

\section{EXPERIMENTAL}

3.1 Synthesis of the new planarizing material, $\mathrm{Si}-12$

The synthesis of the UV curable branched siloxane (epoxy-Si-12) illustrated in Figure 4. The number of silicon atoms has been reduced, which provides access to the greatly simplified synthetic route and the properties of the new material are very similar to those of $\mathrm{Si}-14$. Epoxide groups were selected to enable for curing. Si-12 functionalized with epoxides shows a lower UV shrinkage than the corresponding methacrylate analog. The characterization of the materials was conducted by NMR (VARIAN $400 \mathrm{MHz}$ ), GC/MS (Agilent Technologies 6890N attached with HP-5MS capillary column, Agilent), CI-MASS (Dionex ultimate 3000) and MALDI-MASS (VARIAN Pro MALIDI 12 Tesla).

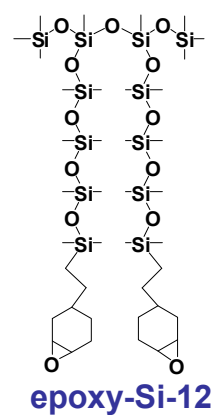

Figure 4. Structure of epoxy-Si-12

\subsection{Properties of epoxy-Si-12}

The weight percent of silicon in the compound is $30.0 \%$ which far exceeds the $12 \%$ threshold normally required [7]. The vapor pressure was measured by submitting a sample of Si-12 to a series of freeze thaw cycles and then allowing the material to come to liquid-vapor equilibrium at room temperature and measuring the pressure in the vessel. The viscosity was measured by a Physica MCR 500 Rheometer. The UV shrinkage was calculated from the difference of film thickness on substrates by the use of an ellipsometer (J. A. Woollam) before and after the UV cure.

\subsection{Spin coating of epoxy-Si-12}

An initial spin coating study of epoxy-Si-12 was carried out on plain substrates. No solvent was added to the formulation. Only 0.7 wt. \% of the photo acid generator (PAG) illustrated in Figure 5, was added to the epoxy-Si-12 to initiate crosslinking under UV exposure. The spin rate of the substrates was set to $2500 \mathrm{rpm}$. A volume of $200 \mu \mathrm{l}$ of epoxy-Si-12 was dispensed on plain substrates (1 inch x 1 inch) and the substrates were spun for differeing periods of time whereupon they were cured by exposure to UV light. The film thickness after UV exposure was measured by ellipsometry. All procedures were carried out in a yellow room (UV cut-off filtered room). 


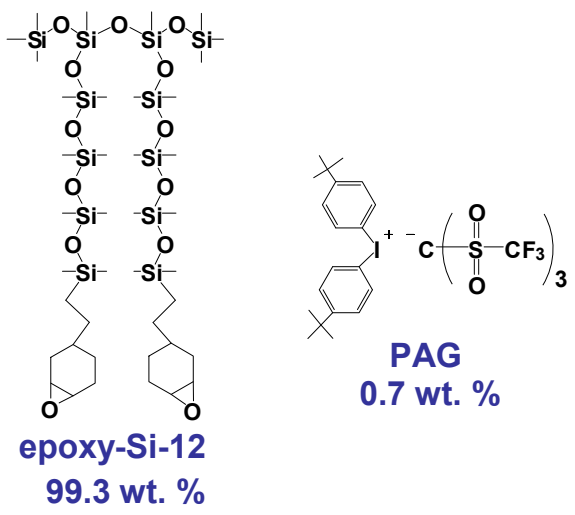

Figure 5. Formulation used to crosslink under UV exposure

3.4 Planarizing properties

The planarizing properties of epoxy-Si-12 were investigated over a patterned surface. Substrates with trench structures (width; $200 \mathrm{~nm}$, depth; $\mathrm{d}=1000 \mathrm{~nm}$ ) were prepared as shown in Figure 6.

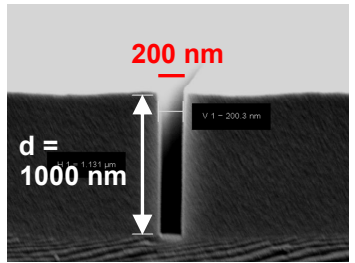

Figure 6. Test substrate for planarizing study

Epoxy-Si-12 with PAG was spin coated onto the test substrates at $2500 \mathrm{rpm}$ for varying spin times, 15, 30, 60, 120 and 300 seconds, to achieve different film thicknesses. Then each of the samples was cured by exposure to UV radiation. At two different points on the films the film thickness was measured by SEM. One was the thickness over the plain substrate $\left(h_{0}\right)$. The other was the thickness over a trench structure $(h)$. The difference in height between $h_{0}$ and $h$ was assigned $h_{c}$. The degree of planarization (DOP) was calculated from $d$ and $h_{c}$ [8]. For example, if $h_{c}$ is $0.3 \mu m$ and $d$ is $1.0 \mu \mathrm{m}$, DOP based on the equation below would be $70 \%$. The experimental procedure is illustrated in Figure 7 below.

\section{Experimental procedure}

\section{1) Spin coat epoxy-Si-12 \& cure on patterned substrate}

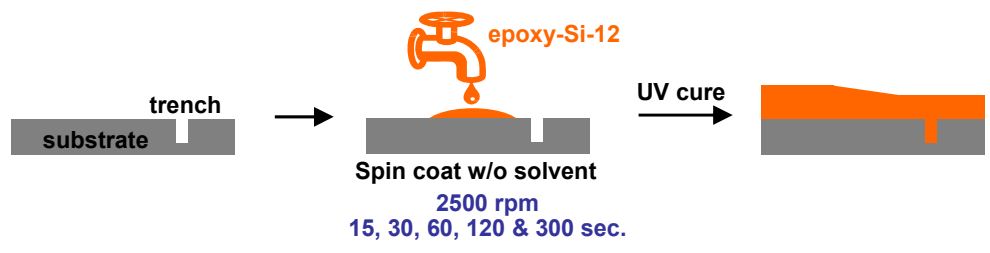

2) Measure the thickness at two points $\left(h_{0}\right.$ and $\left.h\right)$

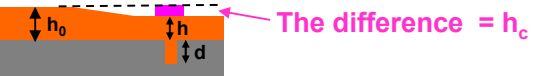

3) Calculate Degree of Planarization (DOP \%)
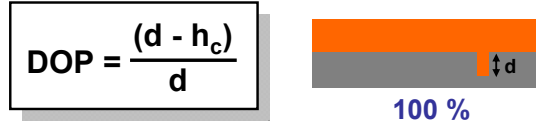

$100 \%$
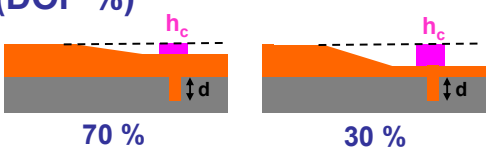

Figure 7. The procedure to investigate planarizing properties 


\subsection{S-FIL/R demonstration using epoxy-Si-12}

An S-FIL/R demonstration was carried out using epoxy-Si-12. The process flow, the formulation used, and the target stack dimensions can be seen in Figure 8. The process consists of several steps; 1) substrate preparation, 2) imprint test features, 3) planarization using epoxy-Si-12, 4) $\mathrm{CHF}_{3}$ etch, 5) $\mathrm{O}_{2}$ etch.

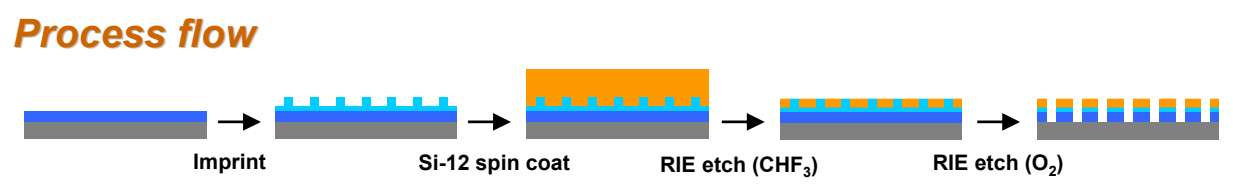

\section{Materials}

Nissan Chemical's layer, NCI-NIL-01 (organic)

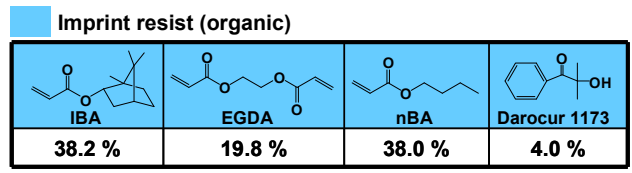

Epoxy-Si-12 (high silicon content)

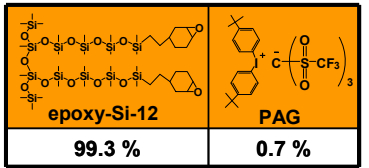

\section{Target stack dimensions}

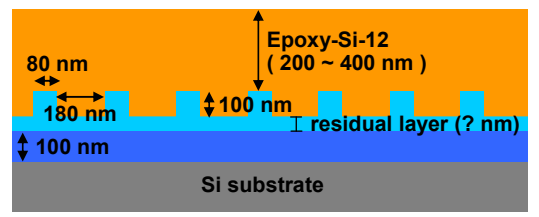

Figure 8. Demonstration of S-FIL/R using epoxy-Si-12

In the first step, substrates coated with an underlayer, NCI-NIL-01 (Nissan Chemical Industries, Ltd., Japan), were prepared. The purpose of the underlayer or transfer layer is to improve adhesion and to provide a mask for subsequent etch process. In the second step, imprints were carried out on an, Imprio $100^{\circledR}$ (Molecular Imprints Inc., USA) Step and Flash Imprint Lithography tool installed at the University of Texas at Austin. A quartz template with $80 \mathrm{~nm}$ lines and $180 \mathrm{~nm}$ spaces was fabricated by the University of Texas at Austin. The template was pre-treated with a fluorinated surface treatment (Tridecafluoro-1,1,2,2-tetrahydro octyldimethylchlorosilane from Gelest Inc., USA) to improve template release [9]. In the third step, a $\mathrm{CHF}_{3}$ etch was carried out on an Oxford Plasmalab 80 Plus to remove excess epoxy-Si-12 layer. The etch ratio of epoxy-Si-12 was measured to enable a timed process that led to the correct etch depth. In the last step, an $\mathrm{O}_{2}$ etch was carried out to break through the organic layer. An SEM (Zeiss Neon 40) was used to measure stack thicknesses and etch depths.

\section{RESULTS AND DISCUSSION}

4.1 Synthesis of a new planarizing material, Si-12

A new synthetic route to Si-12 was developed and is illustrated in Scheme 1 [10]. The optimized route to the final product, Si-12, took only two steps. This is a tremendous improvement over the Si-14 synthesis [6]. The starting materials are inexpensive and commercially available. The new synthetic route has now been shown to be easily scalable and therefore suitable for industry.

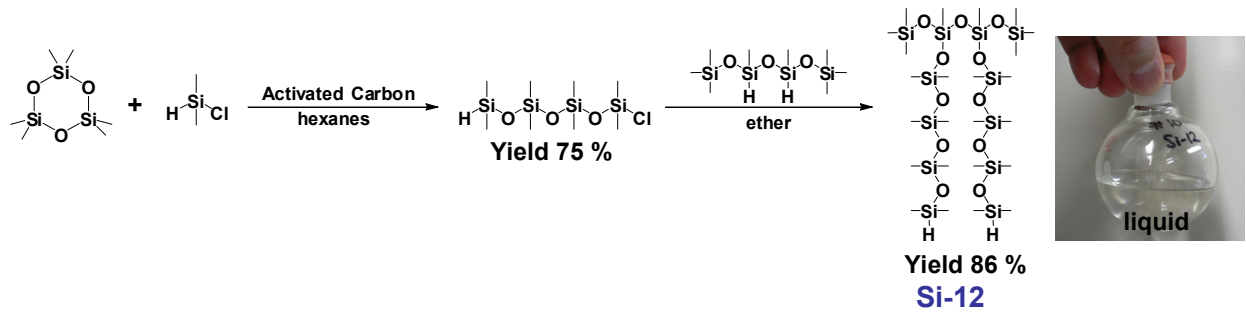

Scheme 1. Efficient synthetic route for Si-12 
$\mathrm{Si}-12$ has two Si-H bonds, which can used to incorporate UV curable functionality on branched siloxane. The synthetic path to epoxy-Si-12 is shown in Scheme 2. The hydrosilylation [11] reaction was successfully carried out using commercially available catalyst and the pure product was recovered in high yield. The details of this synthesis will be published elsewhere.
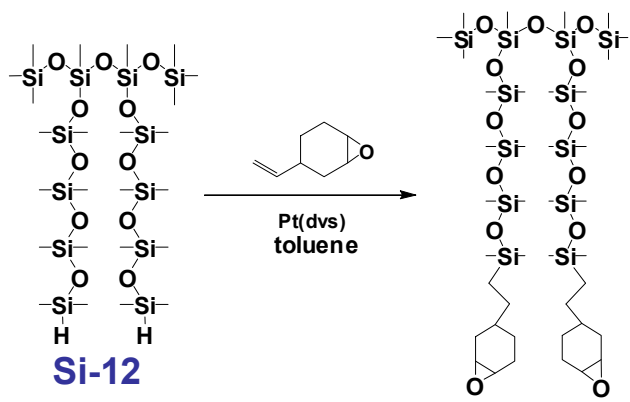

Yield $87 \%$

Epoxy-Si-12

Scheme 2. Synthesis for epoxy-Si-12

\subsection{Properties of epoxy-Si-12}

Epoxy-Si-12 is a slightly yellowish liquid. It is speculated that the color of the product is due to very small amounts of residual catalyst. If the material is to be used in a metal sensitive process, more work must be done to insure quantitative removal of the catalyst The properties of the material are summarized in Figure 9.

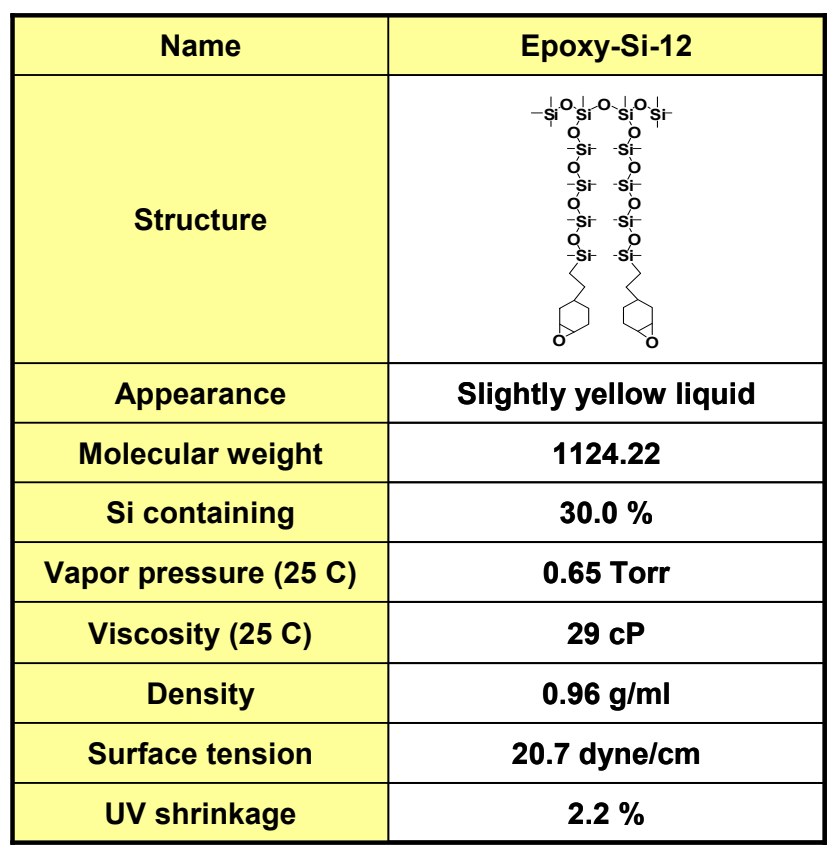

Figure 9. Properties of epoxy-Si-12

\subsection{Spin-coat study of epoxy-Si-12}

A spin-curve is shown in Figure 10. Since there is no solvent used in the process, the thickness of the film depends on the amount initially dispensed and the spin time. It should be noted that this is very different behavior that that which is observed when spin coating solutions of polymers, such as photoresist. The result of this study indicated that 150 seconds of spin time provided a film thickness of less than $1.0 \mu \mathrm{m}$ for this substrate material and the $200 \mu \mathrm{l}$ dispense volume. These data were useful for subsequent planarizing studies and the S-FIL/R demonstration. 


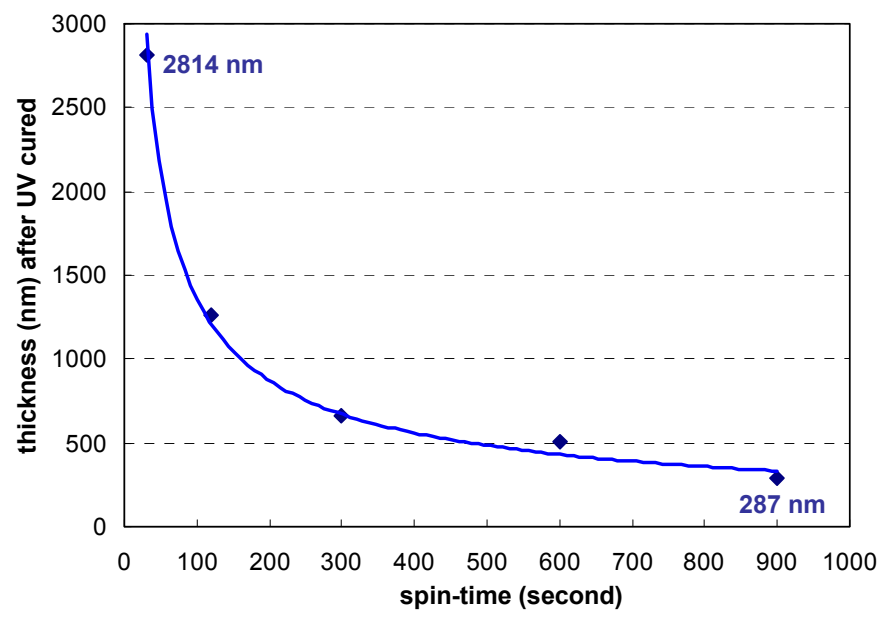

Figure 10. Spin-curve of epoxy-Si-12

\subsection{Planarizing properties}

The planarizing results are provided in Figure 11. For the first experiment (15 seconds spin time) the $\mathrm{h}_{0}$ value was 4.22 $\mu \mathrm{m}$ and the $\mathrm{h}$ value was $4.22 \mu \mathrm{m}$ resulting in $100 \%$ DOP. But as the spin time was lengthened and $\mathrm{h}_{0}$ decreased, the difference in film thickness $\left(\mathrm{h}_{\mathrm{c}}\right)$ changed, which resulted in a decrease in DOP.

\begin{tabular}{|c|c|c|}
\hline \multirow{2}{*}{ Spin time } & \multicolumn{2}{|c|}{ Thickness } \\
\cline { 2 - 3 } & $\mathrm{h}_{0}$ & $\mathrm{~h}$ \\
\hline $15 \mathrm{sec}$. & $4.22 \mathrm{um}$ & $4.22 \mathrm{um}$ \\
\hline $30 \mathrm{sec}$. & $2.91 \mathrm{um}$ & $2.75 \mathrm{um}$ \\
\hline $60 \mathrm{sec}$. & $2.08 \mathrm{um}$ & $1.69 \mathrm{um}$ \\
\hline $120 \mathrm{sec}$. & $1.36 \mathrm{um}$ & $0.85 \mathrm{um}$ \\
\hline $300 \mathrm{sec}$. & $0.83 \mathrm{um}$ & $0.36 \mathrm{um}$ \\
\hline
\end{tabular}
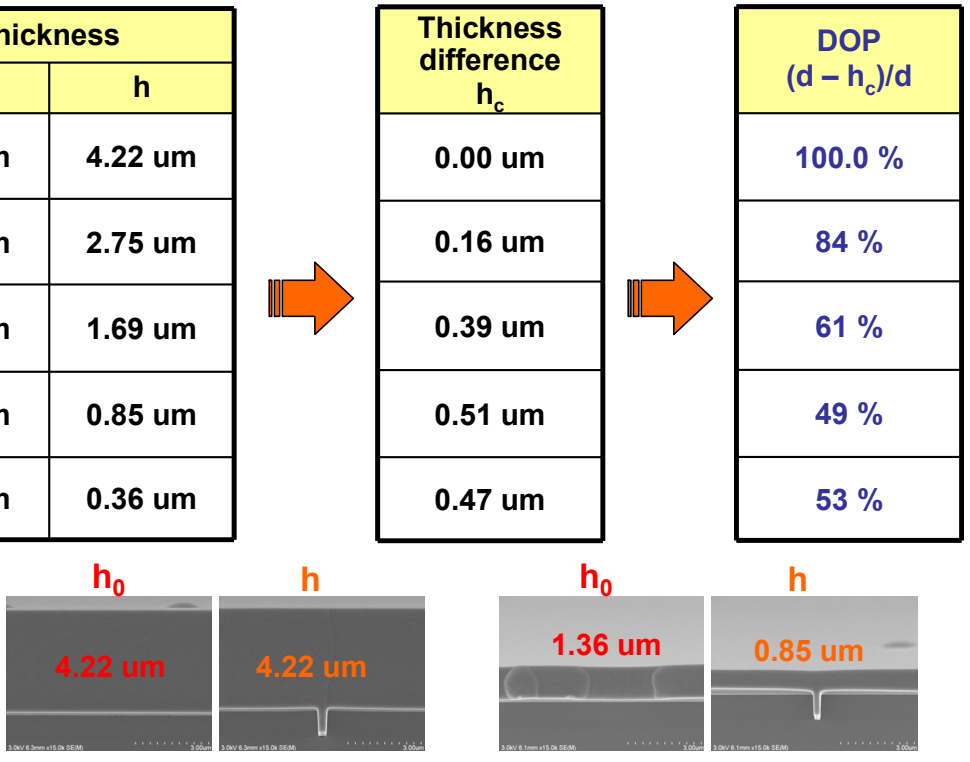

Spin time $15 \mathrm{sec}$.

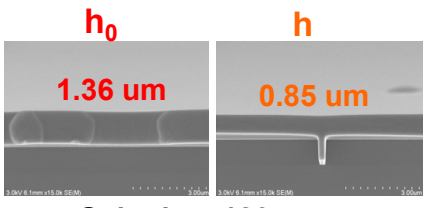

Spin time $120 \mathrm{sec}$.

Figure 11. The results of planarizing study using epoxy-Si-12

The critical DOP values were calculated using the equation shown in Figure 12 for comparison with the measured data [8]. The value depends on the film thickness $\left(\mathrm{h}_{0}\right)$, overetch rate $(\eta)$, UV shrinkage of the material $(\varepsilon)$, and the trench depth (d). The critical DOP is the minimum requirement for a successful etch process. 


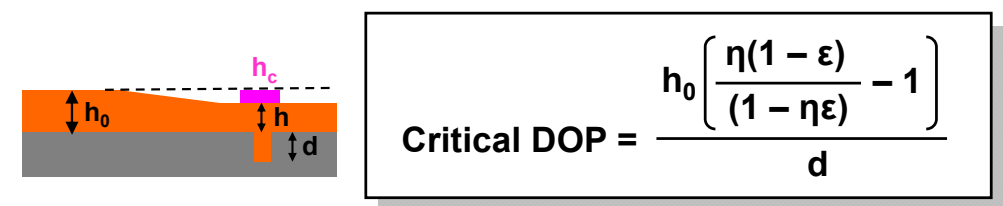

thickness $\left(h_{0}\right)$, overetch rate $(\eta)$, UV shrinkage $(\varepsilon)$, and trench depth (d)

Figure 12. The equation for critical DOP value

Figure 13 shows the correlation between $\mathrm{h}_{0} / \mathrm{d}$ ratios and DOP values. All experimental DOP values met the critical DOP requirement. The results indicate that epoxy-Si-12 has the potential to be an excellent planarizing layer for subsequent processes. In future work, simulations of the planarizing process could be useful for discussion of the planarizing properties of epoxy-Si-12, especially the DOP value at 300 seconds spin time where the results did not follow the general trend. Further planarizing studies using different test substrates and patterns such as multiple trenches, or via structures, are required to fully understand the planarizing properties of epoxy-Si-12.

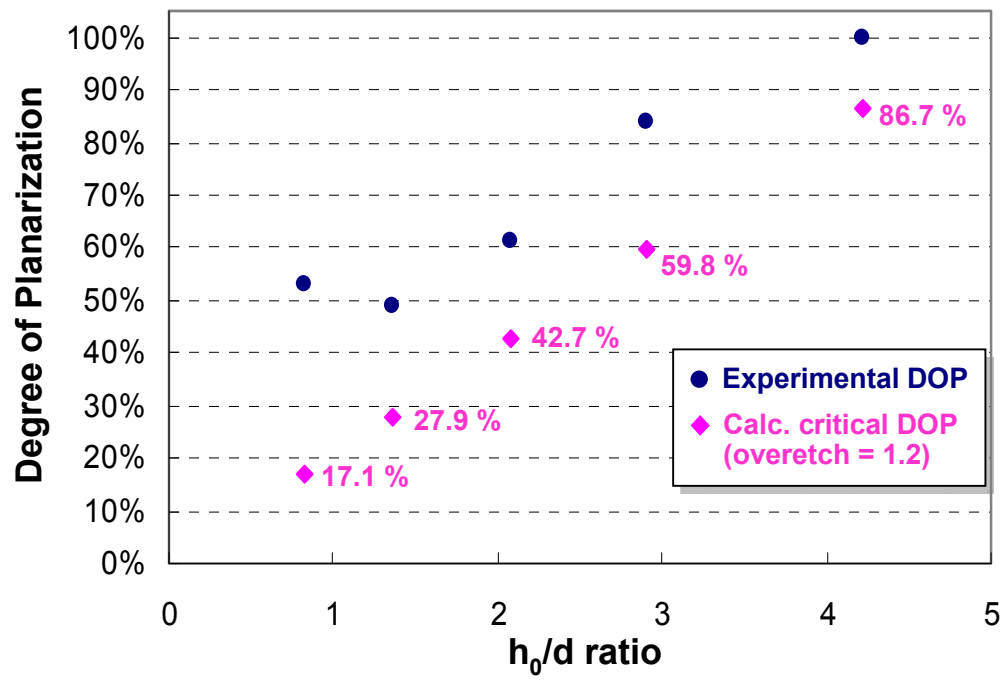

Figure 13. The correlation between $\mathrm{h}_{0} / \mathrm{d}$ and DOP

4.5 S-FIL/R demonstration using epoxy-Si-12 resist

Following are the results of each step in the S-FIL/R process.

Step 1. NCI-NIL-01 (Nissan Chemical Industries, 1td.) was spin-coated to approximately $100 \mathrm{~nm}$ thickness on bare silicon substrates.

Step 2. Imprints were made with an $80 \mathrm{~nm}$ lines and spaces template on an Imprio 100 were carried out. The imprint resist was Monomat from Molecular Imprints. One of the features of S-FIL is an inkjet system that dispenses the liquid resist onto substrates. The Imprio 100 does not have a high resolution dispense system so larger that optimum drops must be employed. The optimized dispense pattern is illustrated in Figure 14. The optimized resist drop layout resulted in consistent and successful imprint patterning. 


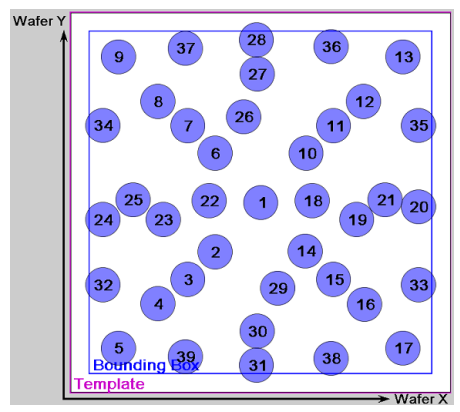

Total resist drop amount: 0.0195 ul Template down velocity: $0.45 \mathrm{~mm} / \mathrm{s}$ Template cavity pressure: $\mathbf{0 . 0 5}$ bar Imprint force: $15 \mathrm{~N}$ Pre UV delay: $120 \mathrm{sec}$.

UV exposure: $20 \mathrm{sec}$.

Resist drop layout

Figure 14. The optimized recipe for S-FIL

An SEM image of an imprint is shown in Figure 15. The residual layer was approximately $52 \mathrm{~nm}$, which is a little thicker than for the normal S-FIL process (less than $20 \mathrm{~nm}$ ). Further optimization such as lowering the resist volume or changing the imprint force, could reduce the residual thickness, but in the case of the S-FIL/R process, this thickness is acceptable because of the planarizing layer will coat and cover the topography.

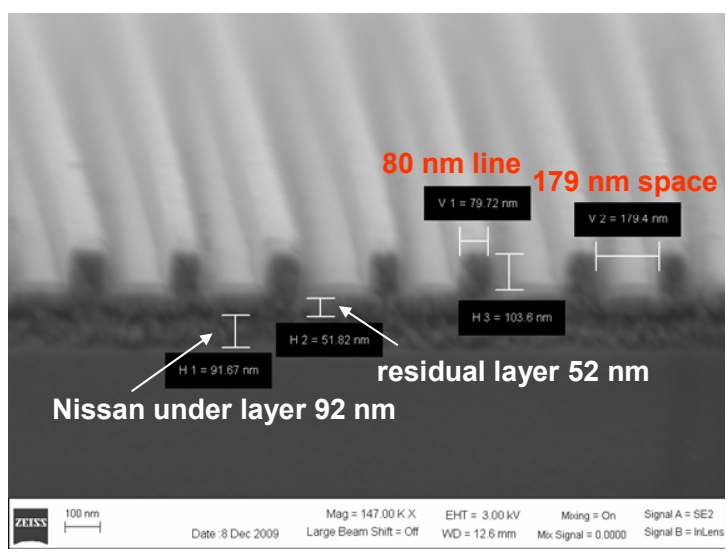

Figure 15. The SEM image of imprint

Step 3. Planarization using epoxy-Si-12 was carried out and an SEM image is shown in Figure 16. The thickness of epoxy-Si-12 layer was $343 \mathrm{~nm}$. The result showed epoxy-Si-12 worked for planarizing layer very well.

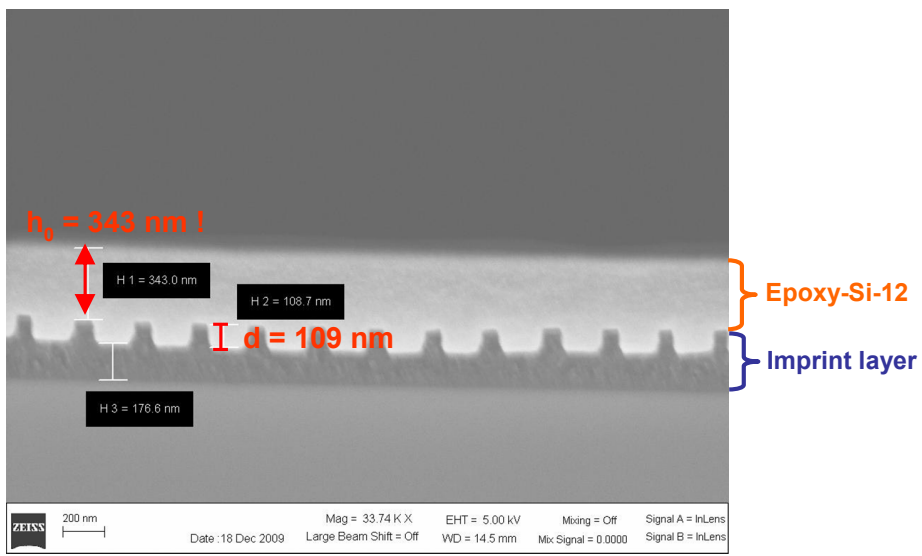

Figure 16. SEM image after planarizing

Step 4. The etch rate of epoxy-Si-12 was determined $\left(\mathrm{CHF}_{3}: 20 \mathrm{sccm}, \mathrm{O}_{2}: 12 \mathrm{sccm}, \mathrm{RF}: 50 \mathrm{~W}, \mathrm{DC}\right.$ bias: $192 \mathrm{~V}$, Pressure: 30 mTorr) and is shown in Figure 17. 


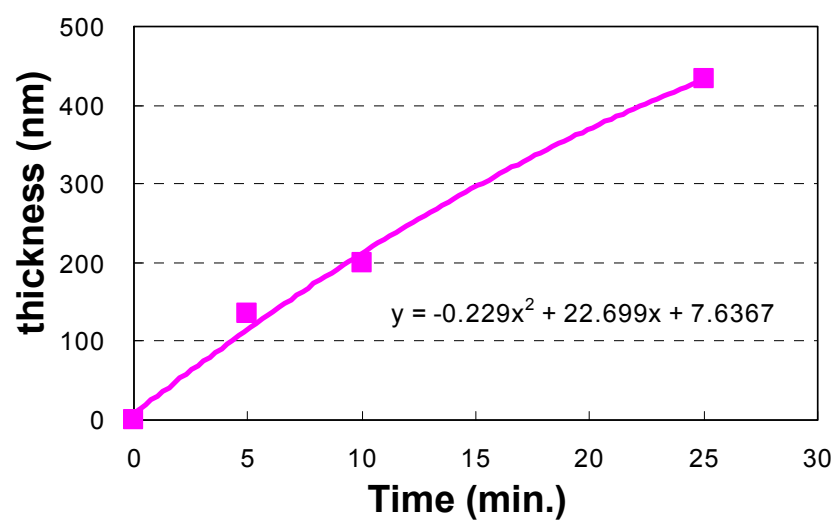

Figure 17. The etch rate of epoxy-Si-12

Figure 18 shows an SEM image after the fluorine etch step. Epoxy-Si-12 was etched down to the top of the imprinted layer after. A total of 10 minutes was required to reach this depth.

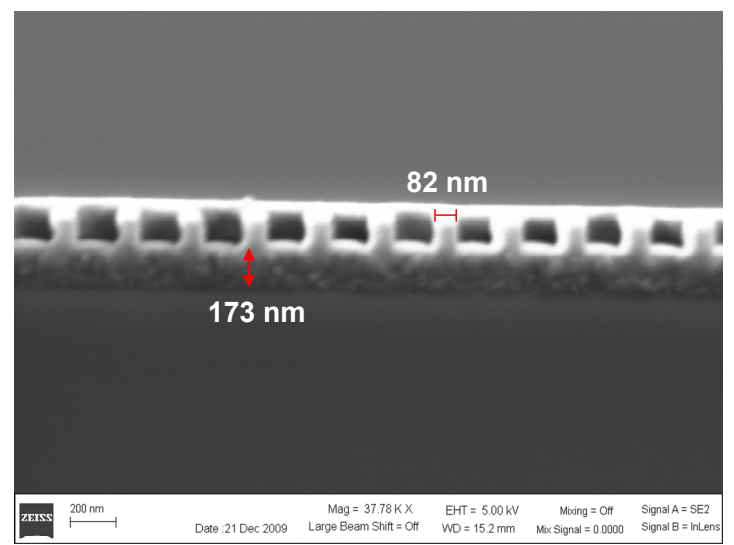

Figure 18. The SEM image after etching the planarization layer

Step 5. $\mathrm{O}_{2}$ etching was carried out to break through the organic layer $\left(\mathrm{O}_{2}: 8 \mathrm{sccm}\right.$, Ar: $30 \mathrm{sccm}, \mathrm{RF}: 90 \mathrm{~W}$, DC bias: 300 $\mathrm{V}$, pressure: 6 mTorr, Etching time: 8 minutes). The organic resist was removed and the desired pattern was obtained as shown in Figure 19. The width of the lines and spaces was reversed compared to the initial imprint pattern, which is expected in reverse-tone S-FIL.

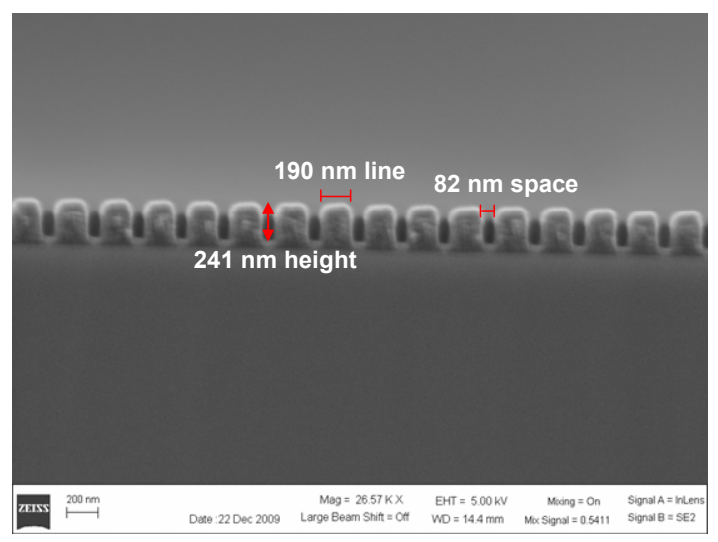

Figure 19. The SEM image after the $\mathrm{O}_{2}$ etch 


\section{CONCLUSION}

This paper describes a UV curable branched siloxane, epoxy-S-12 that is useful for a planarizing material of the sort required for S-FIL/R. Epoxy-Si-12 was synthesized via a convenient new route in high yield. The properties of epoxy-Si12 indicated low viscosity $\left(29 \mathrm{cP}\right.$ at $\left.25^{\circ} \mathrm{C}\right)$, low vapor pressure $\left(0.65\right.$ Torr at $\left.25{ }^{\circ} \mathrm{C}\right)$ and high Si content $(30.0 \%)$, which meet the all of the requirements for a planarizing material for S-FIL/R. Epoxy-Si-12 showed excellent planarizing properties and it easily met the critical DOP in the topography structure studied. S-FIL/R using epoxy-Si-12 was successfully demonstrated and the desired reverse-tone pattern was obtained successfully after the etch process. Other UV curable Si-12 derivatives such as methacryl-Si-12 etc., are being studied currently.

\section{ACKNOWLEDGEMENTS}

The authors want to thank Nissan Chemical Industries Inc, Japan for generous funding. The authors want to thank Dr. Kazuhiko Maeda and Central Glass Co. Ltd., Japan for support of Mr. Tsuyoshi Ogawa and for valuable advice on the chemistry of branched siloxanes. The authors would also like to thank Dr. Marylene Palard, Mr. Gabriel Glenn, and Mr. Ricardo Garcia of the University of Texas at Austin for technical advice and support of the S-FIL/R demonstration.

\section{REFERENCES}

[1] C. Grant Willson, J. Photopolym. Sci. Technol., 22, 147 (2009)

[2] Ken Rygler et al., "Lithography Cost of Ownership: Fact and Fiction", Semiconductor International, 3/12/2010

[3] F. Palmieri et al., "Multi-level Step and Flash Imprint Lithography for Direct Patterning of Dielectrics", Proc. of SPIE, 6151, p. 61510J1-9 (2006)

[4] S. V. Sreenivasan, D. Resnick, and C. G. Willson "Using reverse-tone bilayer etch in ultraviolet nanoimprint lithography", Micromagazine, May, (2001)

[5] Michael W. Lin et al., "Planarization for Reverse-Tone Step and Flash Imprint Lithography", Proc. of SPIE, Vol. 6151, 61512G, (2006)

[6] Jianjun Hao et al., "Photocurable Silicon-Based Materials for Imprint Lithography", Proc. of SPIE, Vol. 6517, $651729,(2007)$

[7] Matthew Colburn et al., "Step and Flash Imprint Lithography for sub-100nm Patterning", Proc. of SPIE, vol. 3997, 453-457 (2000)

[8] Michael W. Lin et al., "Simulation and design of planarizing materials for reverse-tone step and flash imprint lithography", J. Micro/Nanolith. MEMS MOEMS 7(2), 023008 (Apr-Jun 2008)

[9] T. Bailey, B. J. Choi, M. Colburn, M. Meissl, S. Shaya, J. G. Ekerdt, S. V. Sreenivasan, C. G. Willson, "Step and flash imprint lithography: Template surface treatment and defect analysis", J. Vac. Sci. Technol. B 18(6), Nov/Dec, 3572-3577 (2000)

[10] Koji Yoshino et al., "A convenient Synthesis of $\alpha, \omega$-Difunctionalized Linear Dimethylsiloxanes with Definite Chain Lengths", Chemistry Letters, p.2133-2136 (1990)

[11] Chunxin Zhang, Richard M. Laine, "Hydrosilylation of Allyl Alcohol with $\left[\mathrm{HSiMe}_{2} \mathrm{OSiO}_{1.5}\right]_{8}$ : Octa(3hydroxypropyldimethylsiloxy)octasilsesquioxane and Its Octamethacrylate Derivative as Potential Precursors to Hybrid Nanocomposites", J. Am. Chem. Soc., 122, 6979-6988 (2000) 